\title{
Os enunciados da função social da escola nos discursos de educandos jovens e adultos
}

Eduardo Jorge Lopes da Silva Departamento de Educação do Centro de Ciências Humanas, Sociais e Agrárias, da Universidade Federal da Paraíba, João Pessoa, PB - Brasil. eduardojorgels@gmail.com

Márcio Alison Santos da Silva Faculdades Integradas de Patos (FIP). Paraíba, João Pessoa,PB-Brasil. alison_marcio@hotmail.com

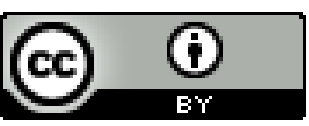

Educação: teoria e prática, Rio Claro, SP, Brasil - elSSN: 1981-8106

Está licenciada sob Licença Creative Common

\section{Resumo}

A escola ainda é uma instituição privilegiada para muitos educandos da modalidade educação de jovens e adultos (EJA), uma vez que oportuniza, entre outras coisas, o acesso ao saber socialmente valorizado e por qualificar esses educandos com os instrumentos da leitura, da escrita e dos fundamentos básicos da matemática. O presente artigo investiga os discursos sobre a função social da escola, de educandos jovens e adultos de uma escola pública, localizada na comunidade Mumbaba I, no Distrito Industrial de João Pessoa/PB. Aporta-se na análise do discurso, na perspectiva arqueológica preconizada por Foucault (2000). Os dados foram coletados a partir de entrevistas semiestruturadas. Os resultados permitiram identificar discursos que convergem para um entendimento de que a escola é a porta de acesso aos códigos linguísticos, à formação do caráter e à formação profissional, elementos essenciais que permitem às camadas populares uma melhor interação social e as ferramentas para o exercício pleno da cidadania.

Palavras-chave: EJA. Função social da escola. Discurso.

\section{The social function of school and the discourses on education by young and adults students}

\section{Abstract}


The school is still a privileged institution for many students from education modality for youths and adults (EJA), since it provides an opportunity, among other things, the access to socially valued knowledge and qualifies these students with tools of reading, writing and basic fundamentals of mathematics. This paper investigates the discourses on the social function of school from students and young adults in a public school located in the community Mumbaba I, in the industrial district of João Pessoa / PB. The theoretical framework is based on the discourse analysis from an archaeological perspective advocated by Foucault (2000). The data were collected through semi-structured interviews. The results showed discourses that converge to an understanding that the school is the gateway to the linguistic codes, the character formation and professional training which are essential elements that provide students from lower classes a better social interaction and tools for their full achievement of citizenship.

Keywords: EJA. Social function of school. Discourse.

\section{Introdução}

A Educação de Jovens e Adultos (EJA) é um tema que tem se mantido no centro das discussões mundiais desde 1949, através da realização de Conferências regionais e internacionais, efetivadas pela Organização das Nações Unidas para a Educação, a Ciência e a Cultura (UNESCO) ${ }^{1}$.

No cenário brasileiro encontram-se resquícios dessa modalidade de ensino desde a época do descobrimento, através da ação catequista dos jesuítas, entre adolescente e população indígena jovem, apontam os estudos realizados por Paiva (2003). Entretanto, foi a partir da aprovação do Decreto no 19.513, de 25 de agosto de 1945, que a educação de adultos teve garantidos a oficialidade e recursos financeiros no Brasil (CASTRO, 1999).

Apesar disso, a história da EJA, no Brasil, foi construída através de campanhas descontínuas, não havendo, portanto, mudanças significativas em favor de uma política pública que a tratasse como prioridade para consolidá-la como processo formativo imprescindível ao exercício da cidadania dos educandos jovens e adultos².

\footnotetext{
1 A Primeira Conferência Internacional de Adultos foi realizada em Elsinor, Dinamarca (1949), com a participação de representantes dos países da Europa Ocidental, logo após a II Guerra Mundial. Assim, essa conferência atribuiu à educação de adultos a tarefa de desenvolver ações capazes de construir o respeito recíproco entre os povos, a estima mútua dos seus valores culturais, a tolerância cultural, étnica, ideológica etc. Também, a construção de uma cultura em prol da paz no mundo (CASTRO, 1999. p. 24). As demais foram: a II CONFINTEA, realizada em Montreal, no Canadá, em 1960; a III CONFINTEA, realizada em Tóquio/Japão, em 1972; a IV CONFINTEA, realizada em Paris/França, em 1985; a V CONFINTEA teve lugar em Hamburgo/Alemanha, em 1997; e a VI CONFINTEA, realizada em Belém, estado do Pará, Brasil, em 2009.

2 Lembramos que, ao longo de sua história, a EJA foi limitada a campanhas de alfabetização. Com a promulgação da Lei de Diretrizes e Bases da Educação Nacional, LBD 9.394/96, ela recebeu o status de modalidade educativa da educação básica. Essa condição a amplia para uma compreensão de educação que a contempla desde a alfabetização até o ensino médio.
} 
De 1995 até 2002, a política do governo brasileiro centrou seus esforços na valorização do ensino fundamental na faixa etária obrigatória, objetivando a superação da repetência, da evasão escolar, bem como a elevação do percentual de concluintes no ensino fundamental. Essa iniciativa, apregoada pelo MEC, eliminaria a necessidade de prover a EJA no país (SILVA, 2005), a qual passou a ser conduzida por mais um programa, dessa vez, dirigido por organização não-governamental, Alfabetização Solidária, da ex primeira dama D. Ruth Cardoso.

Nesse período, a escola estava aberta a todos, no entanto, sem garantir a continuidade do processo escolar de milhares de alunos e nem a qualidade do ensino, propiciando, dessa forma, a produção e a reprodução do fracasso escolar e endossando a “[...] formação continuada de grandes contingentes de jovens e adultos desescolarizados e virtualmente alijados da batalha pelo emprego e pela conquista da cidadania" (SCOCUGLIA, 1999, p. 101).

Em meados da década de 1990 (1996 a 1997), assistiu-se à ascensão e queda da Comissão Nacional de Educação de Jovens e Adultos (CNEJA); o surgimento dos fóruns de educação de jovens e adultos e dos Encontros Nacionais de EJA, conhecidos por ENEJA's (SILVA, 2008; SILVA, 2005) ${ }^{3}$. Isso significou uma mobilização da sociedade, cobrando dos poderes públicos, principalmente da esfera federal, medidas as quais pudessem melhor contemplar as políticas públicas para a EJA no Brasil.

No campo da educação de jovens e adultos, esse processo é particularmente
nítido, por ancorar-se na história, tradição e práticas dos movimentos de educação
e cultura popular. A convergência desses dois movimentos colocou no centro do
debate o conceito de serviço público não estatal e instaurou uma tendência ao
desenvolvimento de políticas públicas de formação de jovens e adultos em regime
de parceria entre organismos governamentais e não governamentais, cujos
distintos significados, configurações e orientações encontram-se em disputa nos
espaços públicos de gestão compartilhada conformados por essas mesmas políticas
(DI PIERRO, 2000, p. 274).

Quanto aos fóruns de EJA e aos ENEJA's, eles objetivam se configurar em um espaço de pressão política no intuito de influenciar na criação e acompanhamento de políticas públicas nas três esferas do poder (municipal, estadual e federal). É um movimento que

\footnotetext{
${ }^{3}$ Sobre o surgimento e a importância política exercida pelos Fóruns de EJA no Brasil, no final dos anos de 1990 e início do século XXI, ver as seguintes publicações de Eduardo Jorge Lopes da Silva. A primeira, Fórum de Educação de Jovens e Adultos: uma nova configuração em movimentos sociais, publicada pela editora da UFPB, em 2005 e, a segunda, O papel político dos Fóruns de Educação de Jovens e Adultos, publicada pela editora da UEPB, em 2008.
} 
ainda pode ser considerado suprainstitucional e suprapartidário, dependendo da forma organizacional assumida em cada estado.

Silva (2005) compreende os Fóruns de EJA como novos movimentos sociais, os quais reúnem diferentes atores sociais em torno de um único objeto: fomentar políticas públicas para esta modalidade da educação básica. Caracterizam-se, ainda, como espaços de articulação informal e intersetorial; como espaços de socialização e intercâmbio de experiências, e como espaços que possuem caráter formativo e informativo.

As experiências dos ENEJAs ajudaram a articular diversos interlocutores para discutir e propor políticas públicas para a EJA, em nível nacional. Os ENEJAs significam a representação macro dos Fóruns de EJA e se constituem em espaço para "[...] exercitar o convívio e o diálogo na diversidade, expressando a pluralidade de concepções e formas de atuação dos seus integrantes. [...] criar condições e meios para uma maior articulação nacional entre os diversos Fóruns" (ENEJA, 2000, p. 3).

Em 2003, com a chegada de um governo, cujo Presidente da República foi oriundo das camadas populares, observou-se a efervescência dada à EJA através da criação do Programa Brasil Alfabetizado, motivando a sociedade civil, os estados, os municípios e as organizações não-governamentais a promoverem EJA em todo país. Este se configurou como mais um programa governamental em nível de alfabetização de jovens e adultos, repetindo, portanto, a história da EJA por meio de programas.

Diante desse breve panorama, objetivamos, com este estudo, analisar os enunciados presentes nos discursos referentes à função social da escola na Educação de Jovens e Adultos. Para tanto, nos apropriamos da análise arqueológica, preconizada por Foucault em sua obra Arqueologia do Saber. Para esse filósofo:

\footnotetext{
A arqueologia busca definir não os pensamentos, as representações, as imagens, os temas, as obsessões que se ocultam ou se manifestam nos discursos; mas os próprios discursos, enquanto práticas que obedecem a regras [...] Não se trata de uma disciplina interpretativa: não busca um 'outro discurso' mais oculto. Recusa-se a ser 'alegórica' (FOUCAULT, 2000a, p. 159).
}

Outro ponto importante para se entender essa perspectiva de análise, a qual difere de outras abordagens da Análise de Discurso (AD), é o fato de que, para Foucault, o que deve ser analisado é o que está posto. O autor não se preocupa com a interpretação, mas com a análise dos enunciados. 
A análise enunciativa só pode se referir a coisas ditas, a frases que foram realmente pronunciadas ou escritas, a elementos significantes que foram traçados ou articulados [...] se mantém fora de qualquer interpretação; às coisas ditas, não pergunta o que escondem [...] (FOUCAULT, 2000a, p. 126).

Foucault em sua proposta de análise arqueológica “[...] anuncia que só vai se ocupar dos enunciados" (DELEUZE, 2006, p. 13). Mas o que são enunciados e discursos? 0 enunciado está para além de uma estrutura frasal. Foucault exemplifica que o enunciado pode ser encontrado em uma tabela, em um livro de contabilidade, em uma fórmula de álgebra, enfim, em tudo isso é possível identificar um dado enunciativo e não apenas circunscrevê-lo ou defini-lo "[...] pelos caracteres gramaticais da frase" (DELEUZE, 2006, p. 93). O enunciado, portanto, é compreendido como

[...] uma função de existência que pertence, exclusivamente, aos signos, e a partir da qual se pode decidir, em seguida, pela análise ou pela intuição, se eles 'fazem sentido' ou não, segundo que regra se sucedem ou se justapõem, de que são signos, e que espécie de ato se encontra realizado por sua formulação (oral ou escrita) [...] ele não é em si mesmo uma unidade, mas sim uma função que cruza um domínio de estruturas e de unidades possíveis e que faz com que apareçam, com conteúdos concretos, no tempo e no espaço (FOUCAULT, 2000a, p. 99).

Consequentemente, os enunciados estão vinculados aos signos da língua. Eles surgem a partir da linguagem, da forma de expressão de uma dada sociedade. Não se configura em algo transcendente, mas em algo concreto a partir da linguagem expressa pelos signos. O enunciado também não se constitui em um elemento neutro ou isolado. Ele está presente em um campo de relações com outros enunciados, ou seja:

[...] desde sua raiz, ele se delineia em um campo enunciativo onde tem lugar e status, que the apresenta relações possíveis com o passado e que the abre um futuro eventual, qualquer enunciado se encontra assim especificado: não há enunciado [...] livre, neutro e independente; mas sempre um enunciado fazendo parte de uma série ou de um conjunto, desempenhando um papel no meio de outros, nele se apoiando e nele se distinguindo [...] (FOUCAULT, 2000a, p. 114).

Quanto ao discurso, esse é "[...] constituído por um conjunto de sequência de signos, enquanto enunciados, isto é, enquanto lhes podemos atribuir modalidades particulares de existência [e] que se apóia em um mesmo sistema de formação" (FOUCAULT, 2000a, p. 124). Podemos, por conseguinte, compreender que existe uma interdependência entre discurso e enunciado, ou seja, o discurso é definido a partir de um campo enunciativo. Portanto, são os enunciados dentro de uma mesma formação discursiva que definirão o tipo de discurso. Exemplo disso é o discurso que pretendemos analisar neste artigo: o discurso sobre a função 
social da escola, a partir de enunciados formulados oralmente, obtidos de sujeitos inseridos no campo da EJA. Vale esclarecer que eles não são, segundo essa perspectiva, os criadores de tais discursos.

O discurso, assim concebido não é a manifestação, majestosamente desenvolvida, de um sujeito que pensa, que conhece, e que o diz: é ao contrário, um conjunto em que podem ser determinadas a dispersão do sujeito e sua descontinuidade em relação a si mesmo ( FOUCAULT, 2000b, p. 61-62).

A partir disso, o corpus de análise se constitui de enunciados de dois alunos $\left(E^{4} 1\right.$ e $E$ 2, com idades de 20 e 29 anos, respectivamente) e duas alunas (E3 e E4, com idades de 45 e 48 anos, respectivamente) da modalidade EJA, em processo de alfabetização, do anexo da Escola Municipal de Ensino Fundamental João Monteiro da Franca, situada no bairro Mumbaba I, na cidade de João Pessoa. Nessa escola, funcionam duas salas de aula de EJA com os Ciclos I e II. Esse bairro possui uma comunidade pobre, composta por proletários assalariados, subempregados, desempregados, camelôs etc.; é periférico e com característica de zona rural, vizinho ao Distrito Industrial de João Pessoa.

Nem todos os sujeitos entrevistados encontravam-se alfabetizados ainda, apesar de terem frequentado, na infância ou fase adulta, os bancos escolares. O tempo médio de escolarização de todos os entrevistados é de 6,3 anos de permanência na escola. Dos quatro entrevistados, três declararam ter iniciado sua vida escolar aos 6 anos de idade e ter permanecido na escola por, em média, 2 anos.

A pesquisa se caracteriza eminentemente qualitativa e utilizou a entrevista semiestruturada como instrumento para coletar as informações. Com base na perspectiva de análise do discurso focaultiano (análise arqueológica), procuramos extrair categorias, as quais nos possibilitassem descrever os enunciados sobre a função social da escola, segundo os educandos da EJA.

\section{0 discurso da função social da escola na EJA}

A escola, para muitos, ainda é um espaço privilegiado de acesso ao saber socialmente valorizado. Por isso ela é considerada o local singular de trabalho com os conhecimentos produzidos ao longo da história da humanidade; ela também possui, como função social, a responsabilidade de construir saberes indispensáveis para a inserção social de crianças,

\footnotetext{
${ }^{4}$ Lê-se: entrevistado. 
jovens e adultos, além de ser responsável pela formação de cidadãos. Concordando com Galvão (2001, p. 19): “Por vezes, tem-se a impressão de que a única mediação entre as camadas analfabetas ou semi-analfabetas da população e a leitura e a escrita é realizada pela escola".

A escola é um espaço de relações sociais e humanas e, como tal, deveria se apresentar como um locus do cuidar, do formar e do agir humanos em todas as fases do seu desenvolvimento e das diversas formas de construção do conhecimento produzidos por aqueles que a frequentam.

Nesse sentido, concebemos que a escola não pode se fechar no saber considerado verdadeiro e, assim, desprezar outros tipos de conhecimentos que o povo consegue construir a partir de suas práticas cotidianas, diferenciadas das oficialmente estabelecidas. Ela pode oportunizar o diálogo entre os saberes, de modo que do saber popular possam surgir outros saberes, talvez mais aperfeiçoados e mais nítidos para o homem e a mulher das camadas populares. A função social da escola, talvez, pudesse ser aquela que ensine coisas necessárias à vida das populações marginais. Em síntese, como função, lhe caberia:

Ensinar os conteúdos e habilidades necessárias à participação do indivíduo na sociedade; Levar o aluno a compreender a realidade da qual faz parte, situar-se nela, interpretá-la e contribuir para a sua transformação; É fundamental para a formação da cidadania; Todos têm o direito de sonhar e perseguir seus sonhos, realizando projetos individuais e coletivos; A escola pode contribuir, e muito, na mudança da atual sociedade injusta e, muitas vezes, desumana (CENPEC, 1990, p. 19-23).

Assim, o presente artigo faz uma análise arqueológica dos discursos sobre a função social da escola. O discurso está presente nas formulações (orais e/ou escritas) dos homens e de suas instituições. Ora está latente, ora está visível, mas está ali, dizendo sobre como os homens interagem em sociedade. Não é algo abstrato, pelo contrário, material: isto porque as ideias e as intenções são materiais, ou seja, a produção humana é material ou se materializa em suas ações.

Desse modo, os enunciados de alguns alunos da EJA da cidade de João Pessoa apontam para uma sujeição a certa ordem do discurso ${ }^{5}$ escolar, ou seja, a escola

\footnotetext{
${ }^{5}$ De acordo com Foucault (2000b, p. 8-9): “[...] em toda sociedade a produção do discurso é ao mesmo tempo controlada, selecionada, organizada e redistribuída por certo número de procedimentos que têm por função conjurar seus poderes e perigos, dominar seu acontecimento aleatório, esquivar sua pesada e temível materialidade". Portanto, a escola está inserida em uma dada ordem do discurso que procura controlar os
} 
desempenha sua função social de ensinar ou de transmitir os conteúdos escolares, independentemente de considerar ou não a estrutura socioeconômica do seu aluno. Caso o aluno não aprenda, a culpa é dele, que não se esforça para tanto. A ordem do discurso escolar faz com que alguns alunos da EJA assumam, exclusivamente, o ônus pelo seu fracasso, como constatamos nos seguintes discursos: "Meus estudos sempre foi fraco. Eu não me interessei pelos estudos não! Eu acho que foi falta de interesse mesmo, preguiça! Eu gostava muito de brincar!" (E1, 20 anos). E mais: "Meu estudo, eu não sei se tenho muita vocação! Acho que não! Eu ia somente bagunçar. Não levava a sério!” (E2, 29 anos).

Esses discursos evidenciam os enunciados pelos quais os alunos da EJA, provindos das camadas populares, assumem toda a culpa pelo seu fracasso na escola, negam sua história de vida, suas condições sociais, caracterizadas por trajetórias perversas de exclusão social, de negação dos direitos mais básicos à vida, ao afeto, à alimentação, à moradia, ao trabalho e à sobrevivência (ARROYO, 2005).

O discurso da escola exerce um poder capaz de fazer com que o aluno assuma toda a culpa pelo insucesso escolar. Esses, por sua vez, revelam os enunciados que enaltecem a concepção de educação e de escola tradicional, ou, nos termos de Freire, uma concepção de educação bancária (FREIRE, 2002). Portanto, tais discursos fazem parte de um conjunto de enunciados que estabelecem entre si uma rede de relações, apontando para uma determinada formação discursiva: educação bancária ou educação escolar tradicional.

Além do discurso do fracasso escolar, outro dado retoma a questão de gênero como elemento que diferencia os interesses dos educandos da EJA do meio popular, pela escola. $O$ discurso de gênero é retomado pelos entrevistados no cenário de uma sociedade nordestina, até então muito machista. Um exemplo clássico é que os homens são considerados os provedores, os chefes de famílias, e as mulheres, as cuidadoras, as executoras das funções domésticas ou do lar. Apesar disso, no final do século XX, já se observavam mudanças nessas relações funcionais e de gênero. No Brasil, por exemplo, a participação das mulheres no mercado de trabalho vem crescendo desde a década de 1970 (MATTOS, 2009). Homens e mulheres, a partir de um princípio humano, têm procurado conviver em igualdade legal e respeito mútuo. O movimento feminista da década de 1960 é 
responsável pela maior inserção das mulheres nas atividades sociais extradomésticas (GOHN, 2000).

Para as mulheres entrevistadas, o aprendizado da leitura e da escrita serve para o seu melhor desempenho nas atividades cotidianas, como: fazer feira em um supermercado, comprar um esmalte, para si ou para usar na profissão de manicure, uma atividade hegemonicamente feminina. E, quando estas deixam a escola para procurar uma atividade ou ocupação no mercado de trabalho, buscam atividades tipicamente femininas e que não requerem alto nível de escolarização: ser empregada doméstica, faxineiras ou diaristas, lavadeiras etc.

Esse fato compõe a formação discursiva ${ }^{6}$ da última Pesquisa Mensal de Emprego (PME) do Instituto Brasileiro de Geografia e Estatística (IBGE, 2010), onde os trabalhadores domésticos representavam $7,6 \%$ da população ocupada ${ }^{7}$, nas regiões metropolitanas pesquisadas ${ }^{8}$. Nessa mesma pesquisa, as mulheres representam $94,5 \%$ do total de trabalhadores, sendo que $62,0 \%$ eram dos trabalhadores domésticos pretos ou pardos (IBGE/PME, 2010). Portanto, as mulheres entrevistadas, do meio popular, com pouca ou quase nenhuma escolarização, buscam ocupação no mercado de trabalho nas funções que não requerem maior complexidade em nível de estudos, embora essa realidade esteja mudando em decorrência de uma sociedade cada vez mais tecnodigital e grafocêntrica.

Entre os homens entrevistados, a necessidade de aprender a ler e a escrever está mais voltada para a capacitação profissional, para se conseguir um emprego, o que torna possível que ele continue sendo o provedor da família, o chefe, o que sustenta a casa ${ }^{9}$. Eles ainda estão submetidos à ordem do discurso do mundo do trabalho, que thes empurra para as fábricas ou para as atividades de operários da construção civil, as quais requerem mais força física do que intelectiva. No Brasil, por exemplo, os homens representam $12,6 \%$ dos ocupados, por setor de atividade econômica da construção, e as mulheres, 0,5\%. No âmbito

\footnotetext{
6 Entende-se por Formação Discursiva o conjunto de enunciados que dará origem a um dado objeto (FOUCAULT, 2000a).

7 Os homens, de acordo com os dados do Departamento Intersindical de Estatística e Estudos Socioeconômicos, representavam $0,9 \%$ dos ocupados, por setor de atividade econômica nos serviços domésticos (DIEESE, 2011).

${ }^{8}$ As regiões metropolitanas são: Recife, Salvador, Belo Horizonte, Rio de Janeiro, São Paulo e Porto Alegre.

${ }^{9}$ Isso, apesar do aumento de famílias chefiadas por mulheres: $36 \%$, de acordo com os dados da Pesquisa Nacional por Amostra de Domicílios (PNAD 2009), divulgados pelo Instituto de Pesquisa Econômica Aplicada (IPEA), em 2010. Os homens ainda representavam 64,8\% desta realidade (IPEA/PNAD 2009).
} 
da indústria de transformação, os homens ocupam 14,9\%, e as mulheres, 12,4\% (DIEESE, 2011).

Tais dados constituem uma formação discursiva pela qual a sociedade do século XXI mantém o discurso de que, para as mulheres do meio popular e de baixo nível de escolarização ${ }^{10}$, o trabalho doméstico em casas de famílias ainda é mais fácil de conseguir, enquanto que para os homens, sob as mesmas condições, a atividade de operário, seja na indústria ou na construção civil, os absorvem com maior facilidade. Essa prática discursiva é uma regularidade que tem na Revolução Industrial do século XVIII seu processo embrionário. De lá para cá, as tecnologias vêm se complexificando e as exigências aumentando, excluindo aqueles e aquelas que ainda possuem baixo nível de escolarização, bem como admitindo algumas mulheres em atividades outrora exclusivamente masculinas. Alguns canteiros de obras, por exemplo, poucos na verdade, admitem mulheres-serventes, mulheres-pedreiros etc. A força física, o biótipo e o grau de estudos ainda determinam o tipo de atividade que as pessoas irão desenvolver no meio de produção capitalista. E como a escola se comporta diante destes fatos? Sua função social reforça a divisão entre homens e mulheres no mercado de trabalho?

Nos itens que se seguem, identificamos e analisamos os principais enunciados presentes nos discursos dos sujeitos entrevistados, os quais trazem luzes para os questionamentos anteriormente citados.

\subsection{Os enunciados da função social da escola: "ensinar a ler, a escrever e a matemática para que os alunos possam usar estes conhecimentos no seu cotidiano"}

A sociedade não é algo inerte, pelo contrário, ela está em frequente movimento, mudanças etc. São os sujeitos humanos que constroem, estabelecem regras e leis para poderem conviver mais e melhor, juntos, em sociedade.

\footnotetext{
${ }^{10}$ Ainda, de acordo com dos dados divulgados pelo DIEESE, as regiões metropolitanas pesquisadas, mais o Distrito Federal, apresentaram, juntos, a seguinte distribuição da população economicamente ativa, por nível de instrução e por sexo: analfabetos: Homens: 2,16\% e Mulheres, 1,84\%; Ensino Fundamental Incompleto: Homens: 25,31\% e Mulheres: 20,21\%; Ensino Fundamental Completo: Homens: 12,20\% e Mulheres: 9,4\% (DIEESE, 2011, p. 62). Logo, esses dados confirmam a existência de um contingente de trabalhadores com pouca ou nenhuma escolarização formal. E, são estes que necessitam se qualificar mais profissionalmente, para competir em um mercado de trabalho, o qual tem exigido, em virtude de seu processo de informatização e complexidade dos serviços, trabalhadores com maior escolarização e habilidades interpessoais para atender ao novo cenário.
} 
[...] a sociedade humana nada mais é do que uma complexa teia de indivíduos e grupos interagindo de acordo com significados por eles atribuídos a suas ações, principalmente os significados derivados da cultura, em função de interesses e objetivos interpessoais (VILA NOVA, 2000, p. 199).

Atribui-se à escola a função social, dentre outras, de responsabilizar-se em ajudar as pessoas a agirem nessa teia social com mais disposição para atenderem aos interesses de uma dada sociedade, como, por exemplo, saber decodificar os signos linguísticos. Sem esta habilidade, as pessoas sentem-se apartadas do processo social, com participação limitada e pouca autonomia.

Os discursos dos entrevistados da EJA indicam que a função social da escola é ensinar a ler, a escrever e a manipular a matemática elementar (as quatro operações), para poderem interagir melhor em seu cotidiano. Não se observa a pretensão de voo mais alto no processo de escolarização das camadas populares, alfabetizandas da EJA. Relacionar-se melhor em sociedade, com as coisas práticas do seu dia-a-dia, é uma das atribuições ou função social da escola, de acordo com os seguintes discursos: "Por que antigamente eu ia comprar um esmalte pela cor. Agora não! Agora eu chego em uma casa cosmética e já vou ali certinho no nome do esmalte."(E3, 45 anos). Também:

\footnotetext{
É importante porque a pessoa quando começa a aprender a fazer conta [...] isso aí, a pessoa vai fazer uma compra no supermercado ou na feira, já sabe conhecer as coisas melhor, o dinheiro, né? Somar [...] isso aí a pessoa vai aprendendo mais e mais nos estudos. É bom para aprender mais e mais ainda. Saber escrever é importante para ir ao banco, escrever uma folha no banco, um contra-cheque [...] (E4, 48 anos).
}

Historicamente, as escolas surgem para o meio popular como uma luta pelo acesso aos saberes/conhecimentos até então circunscritos às camadas sociais economicamente mais favorecidas. $\mathrm{O}$ acesso ao saber se limitava às pessoas de posse. "Na Grécia antiga, as escolas eram de iniciativa particular. Os ricos confiavam o ensino elementar de seus filhos a escravos [...]" (NUNES, 2002, p. 37). Na Idade Média, o ensino hegemonicamente estava sob a responsabilidade dos mosteiros a quem os ricos confiavam a educação de seus filhos. Com a Revolução Industrial (Século XVIII), a educação escolar para os filhos dos trabalhadores ainda não era cogitada. Somente a partir do século XIX, ela surge nos Estados Unidos da América. E a duras penas tem se difundido pelo mundo desde o século XX (NUNES, 2002).

No Brasil, por exemplo, a educação escolar para as classes populares aconteceu através de lutas reivindicatórias de uma dada elite intelectual: os denominados pioneiros da 
educação, no início do século XX. Essa luta ainda é constante, não tanto pelo acesso (quase universalizado), mas pela permanência dos alunos nas escolas, melhor qualidade do ensino público e pela valorização dos professores, ou, como alerta Arroyo $(2005$, p. 23$)$, em seu discurso: "[...] o analfabetismo e os baixos índices de escolarização da população jovem e adulta popular são graves indicadores da garantia universal do direito à educação para todos".

Na história da escola pública brasileira existem críticas a um tipo de ensino que dista da realidade do aluno jovem e adulto. Paulo Freire é um dos críticos mais conhecidos. Para esse pensador, a escola deveria estar próxima da realidade dos educandos da EJA. Seus conteúdos deveriam atender aos seus interesses e necessidades.

\begin{abstract}
Assim é que nos parece dever a educação de adultos, entre nós, ser uma educação que estimule no brasileiro a colaboração, a decisão, a participação, a responsabilidade social e política do homem. Disposições mentais que refletem uma categoria do saber que não é apreendida intelectual ou nacionalmente, mas existencialmente, pelo conhecimento vivo dos seus problemas e dos problemas de sua comunidade local. Pela discussão dêsses problemas em suas ligações uns com os outros. Pela criação posterior aos grupos de estudos, dos grupos de ação, através do que o homem vai ganhando experiência e sabedoria. Programa de trabalho que parta do mais simples da vida local - dos buracos das ruas - das poças de lama - da água - das fossas - das muriçocas - da vida econômica da zona das leiras - das indústrias - das suas instituições e agências sociais - da vida religiosa - da vida recreativa - da vida política municipal - até êstes, ou muitos dêstes problemas serem vistos nos planos mais amplos: estadual, regional e nacional. Dados êstes que não devem ser, porém, discursados, mas discutidos (FREIRE, 1958, p. 5).
\end{abstract}

O meio popular procura a escola pública, os cursos de alfabetização, não apenas para aprender a ler e a escrever, mas principalmente para obterem uma aprendizagem da lectoescrita que Ihes possibilite uma aplicabilidade concreta, a exemplo de ler uma bula de remédio, fazer um bolo a partir da leitura da receita etc.

Portanto, para que a escola cumpra com sua função social, segundo os anseios das camadas populares, deveria trazer conteúdos mais próximos da realidade para discutilos em sala de aula junto com os alunos da EJA, no intuito de eles poderem aplicá-los em seu cotidiano. Assim, os entrevistados jovens e adultos do meio popular atribuem à escola a função social de ensinar a leitura e a escrita da língua materna e as operações matemáticas, para que seus educandos possam melhor interagir em sociedade. Nesse sentido, o sistema público somente avançará como público se levar em consideração as formas concretas de vida e sobrevivência dos setores populares (ARROYO, 2005). 


\subsection{Os enunciados da função social da escola: "formação de caráter socialmente aprovado"}

Os discursos sobre a função social da escola de educandos da EJA, em processo de alfabetização, enunciam que cabe à escola impedir que as pessoas entrem na marginalidade, se envolvam com drogas, tráfico, roubo etc., uma vez que parte desse alunado reside em bairros periféricos e em favelas. Ainda, conforme assevera Arroyo (2005), o perfil dos educandos da EJA é formado por jovens e adultos pobres, desempregados ou fazendo parte da economia informal, negros, homens do campo e da cidade. Todos eles vivendo no limite da sobrevivência.

De acordo com um dos entrevistados, a escola é, portanto: “[...] uma casa de aconselhação [...] Porque é um local bom porque se a gente sair de um canto errado e for pra ali a gente fica inteligente. Porque ali ensina tudo de bom... Porque sem o estudo você vai ficar na rua e ser desordeiro [...]" (E2, 29 anos).

Esse enunciado é retomado pelo discurso da responsabilidade social, propagado pela mídia. Tal discurso é assumido tanto por empresas privadas como por órgãos oficiais do estado, através de campanhas e programas, os quais atribuem à escola, dentre as suas funções sociais, afastar as crianças e os jovens da bandidagem, do consumo de drogas etc.

Desde meados do Século XX, tem-se observado que o discurso sobre a função social da escola é um poderoso veículo de ascensão e formação do caráter humano em direção ao bom convívio em sociedade, além de ser transmissor de um tipo de conhecimento acumulado ao longo da história da humanidade (PILETTI, 1999).

Os enunciados sobre a função social da escola, na perspectiva do caráter socialmente aprovado, estão presentes também na Lei de Diretrizes e Bases da Educação Nacional (Lei 9.394/96, art. 22), a qual atribui à educação básica a finalidade de desenvolver o educando, assegurando-lhe uma formação comum indispensável para o exercício da cidadania, progressão no trabalho e nos estudos posteriores.

Assim, a formação de um caráter socialmente aprovado, como função social da escola, enuncia uma dada ordem do discurso pelo qual disciplina o modo de ser das pessoas que desejam obter aprovação social e, com isso, interagir mais e melhor, em busca do exercício da cidadania e de uma vida mais confortável.

\subsection{Os enunciados da função social da escola: "ajudar a conseguir um bom emprego"}


O trabalho na sociedade moderna (ou, como muitos estão denominando, pósmoderna) tem exigido mão de obra cada vez mais qualificada para o mercado de trabalho. No momento histórico atual, o setor produtivo mundial tem se especializado de modo rápido e em níveis cada vez mais complexos. Para muitos setores da produção, o perfil do trabalhador requer bom nível de escolarização, que não é o caso das camadas populares, cujos níveis estão abaixo dos 9 anos de estudos correspondentes a todo o Ensino Fundamental (PNAD, 2009).

Por não possuir escolarização exigida pelo mercado, boa parte dos alunos da EJA recorre àqueles setores específicos da produção (a exemplo da construção civil), aos trabalhos domésticos e ao trabalho informal (biscateiros, vendedores de picolés, espetinhos etc.), para poderem sobreviver e sustentar suas famílias. Esse perfil é característico de países pobres ou de economias emergentes, a exemplo do Brasil.

No Brasil, deparamos com esforços insuficientes para ampliar a escolarização e redução do analfabetismo, o que seria importante, se não pela possibilidade de melhorar a inserção no mercado de trabalho (seja na qualidade deste, seja na renda auferida), pelo menos pela potencial elevação da cidadania e renda para quem se escolariza. As desigualdades de renda, trabalho e escolarização são temas centrais de toda a sociedade brasileira contemporânea. Nossa renda é desigual no espaço e entre as pessoas. $\mathrm{O}$ acesso ao trabalho é desigual, pois existem muitos sem ele e muitos em trabalhos precários e mal remunerados. A escola não é para todos e nem de todos, pois existem milhões fora dela e nela não estão garantidas as condições de aquisição cultural que podem facilitar uma melhor inserção na sociedade de consumo (NAHAS; OLIVEIRA; CARVALHO NETO, 2002, p. 5).

Desse modo, são os mais pobres que, no Brasil, sofrem com a baixa escolarização. Discursos, tais como: "Bem, eu tenho que me interessar pelos meus estudos para eu poder arrumar um bom emprego para mim, né? Porque hoje em dia, um bom emprego só através de um bom estudo" (E1, 20 anos); ou, ainda: "Bem, o propósito da escola é ensinar ao ser humano a aprender a ler, a ter uma cultura melhor, saber conversar [...] arrumar um emprego [...]" (E2, 29 anos), revelam o quanto a escola é importante na vida dessas pessoas.

Sem escolarização elevada, a qual oportunizará as ferramentas mínimas para uma boa qualificação profissional, fica difícil para as camadas populares adentrarem no mercado de trabalho formal. Esses discursos, portanto, são indicativos de que os membros da camada popular acreditam que à escola cabe, como função social, ajudá-los a se inserirem no mercado de trabalho. 
O discurso capitalista para a escolarização e qualificação profissional tem repercutido dentre os membros das camadas populares no Brasil. Todavia, que condições e tipo de escola estão sendo ofertadas para essa demanda? Trata-se de uma questão polêmica, a qual implica em políticas públicas mais austeras para os diversos setores da educação e da sociedade de modo geral. Além disso, a imprescindibilidade ética e o respeito para com as coisas públicas, por parte dos gestores, são outros requisitos que se somam à problemática.

\section{Algumas considerações finais}

No início do artigo, propusemos como objetivo analisar as regularidades enunciativas nos discursos sobre a função social da escola. Entendemos como regularidade a própria atribuição da função social da escola como espaço privilegiado para a aquisição da leitura e da escrita e dos saberes matemáticos básicos. Essa regularidade se materializa no conjunto de enunciados que constituem o discurso de educandos da EJA sobre tal função, conforme registros orais e documentais.

Destarte, observa-se que os programas, as campanhas em prol da EJA têm como pano de fundo a ideia de que é no espaço escolar (oficial ou não oficial) que se aprende a lectoescrita e a matemática. As políticas públicas são construídas em torno dessa ideia reproduzindo-a e reforçando-a.

Outro fio de regularidade é o que corresponde à atribuição da função social de formadora de caráter. Em outras palavras, cabe à escola formar o educando para o exercício da cidadania ao mesmo tempo em que o afasta da marginalidade (envolvimento com drogas ilícitas etc.). O discurso sobre a escola é promovido por órgãos oficiais do Estado, entidades de caráter privado, ONGs, e circula nesses ambientes e em outros, dentre eles, os midiáticos.

Os enunciados acerca da função social da escola apontam, ainda, para outra função: ajudar o indivíduo a conseguir um emprego. O discurso da escola formadora de mão de obra ratifica o discurso do capitalismo pós-moderno, que exige pessoas cada vez mais qualificadas para o mercado de trabalho. Para que o indivíduo entre no processo de qualificação profissional, precisa ter, no mínimo, um bom nível de escolarização.

Por fim, os discursos que circulam sobre a função social da escola na EJA convergem para um entendimento de que ela é essencial para as camadas populares, porque permite a estas o exercício pleno da cidadania, através do acesso aos códigos linguísticos, da formação do caráter e da formação profissional. 


\section{Referências}

ARROYO, M. G. Educação de jovens-adultos: um campo de direitos e de responsabilidade pública. In: SOARES, L.; GIOVANETTI, M. A.; GOMES, N. L. Diálogos na educação de jovens e adultos. Belo Horizonte: Autêntica, 2005. p. 19-50.

BRASIL. Casa Civil. Lei 9394, de 20 de dezembro de 1996. Estabelece as Diretrizes e Bases da Educação Nacional. 5.ed. Brasília: Câmara dos Deputados: Coordenação Edições Câmara, 2010 (Série Legislação, n. 39). Disponível em: <http://bd.camara.gov.br>. Acesso em: 18 nov. 2011.

CASTRO. E. Leitura de adultos com escolaridade tardia. São Luís: UFMA, 1999.

CENTRO DE ESTUDOS E PESQUISAS EM EDUCAÇÃO E CULTURA. A escola e sua função social. São Paulo: CENPEC, 1990 (Coleção Raízes e asas, fascículo 1).

DELEUZE, G. Foucault. Tradução por Claudia Sant'Anna Martins e Renato Ribeiro. São Paulo: Brasiliense, 2006.

DEPARTAMENTO INTERSINDICAL DE ESTATÍSTICA E ESTUDOS SOCIOECONÔMICOS. Anuário das mulheres brasileiras. São Paulo: DIEESE, 2011. Disponível em: < http://portal.mte.gov.br/data/files/8A7C816A31B027B80131B40586FA0B89/anuarioMulher esBrasileiras2011.pdf>. Acesso em: 15 dez. 2011.

DI PIERRO, M. C. As políticas públicas de educação básica de jovens e adultos no Brasil do período 1985/1999. 2000. 314 f. Tese (Doutorado em História e Filosofia da Educação) Pontifícia Universidade Católica de São Paulo, São Paulo, 2000.

ENCONTRO NACIONAL DE EDUCAÇÃO DE JOVENS E ADULTOS, 2, 2000, Campina Grande. Relatório-síntese. Campina Grande: Grupo Articulador, 2000. Digitado.

FOUCAULT, M. Arqueologia do saber. Tradução por Luiz Felipe Baeta Neves. 6. ed. Rio de Janeiro: Forense universitária, 2000a.

A ordem do discurso. Tradução por Laura Fraga de Almeida Sampaio. 6. ed. São Paulo: Loyola, 2000b. 
FREIRE, Paulo. Pedagogia do oprimido. 32. ed. Rio de Janeiro: Paz e Terra, 2002.

A educação de adultos e as populações marginais: mocambos. In: CONGRESSO DE EDUCAÇÃO DE ADULTOS, 2, 1958, Rio de Janeiro. Anais... Rio de Janeiro: Forum EJA. Disponível em: <http://forumeja.org.br/files/relato.segun_.congr_.educ_.adultos.pdf>. Acesso em: 24 mar. 2013.

GALVÃO, A. M. de O. Cordel: leitores e ouvintes. Belo Horizonte: Autêntica, 2001.

GOHN, M. da G. Teoria dos movimentos sociais: paradigmas clássicos e contemporâneos. 2. ed. São Paulo: Loyola, 2000.

INSTITUTO BRASILEIRO DE GEOGRAFIA E ESTATístICA. Pesquisa Mensal de Emprego: PME: algumas das principais características dos trabalhadores domésticos vis a vis a população ocupada. Disponível em: <http://www.ibge.gov.br>. Acesso em: 14 out. 2012.

Pesquisa Nacional por Amostra de Domicílios: síntese de indicadores 2009. Rio de Janeiro: IBGE, 2010. Disponível em: <http://www.ibge.gov.br>. Acesso em: 12 out. 2012.

MATTOS, A. H. G. A ocupação feminina no mercado de trabalho: desafios para a gestão contemporânea das organizações. Gestão Contemporânea, Porto Alegre, ano 6, n. 6, p. 2343, jan./dez. 2009. Disponível em: <http://seer2.fapa.com.br/index.php/arquivo/index>. Acesso em: 12 out., 2012.

NAHAS, M. I. P.; OLIVEIRA, A. M. de; CARVALHO NETO, A. Acesso à ocupação e a renda versus escolarização no espaço intra-urbano de grandes cidades: o caso de Belo Horizonte. In: SEMINÁRIO SOBRE A ECONOMIA MINEIRA, 10, 2002, Belo Horizonte. Anais... Belo Horizonte: CEDEPLAR:UFMG, 2002. Inserir p.01-14. Disponível em:

<http://ideas.repec.org/s/cdp/diam02.html>. Acesso em: 26 jul. 2008.

NUNES, R. A. da C. Evolução da instituição escolar. In: MENESES, J. G. de C. et al. Estrutura e funcionamento da educação básica. 2. ed. Atualizada. São Paulo: Pioneira Thompson Learning, 2002. p.36-58.

PAIVA, V. Educação popular e educação de adultos. 5. ed. São Paulo: Loyola, 2003.

PILETTI, N. Sociologia da educação. 17. ed. São Paulo: Ática, 1999. 
SCOCUGLIA, A. C. Golpe na educação popular e suas consequências político-educativas. In: MELO NETO, José Francisco de; SCOCUGLIA, Afonso Celso (Orgs.). Educação popular: outros caminhos. João Pessoa: Universitária/UFPB, 1999. p. 111-122.

SILVA, E. J. L. da. O papel político dos Fóruns de Educação de Jovens e Adultos. Campina Grande: Universitária/UEPB, 2008.

Fórum de Educação de Jovens e Adultos: uma nova configuração em movimentos sociais. João Pessoa: Universitária/UFPB, 2005.

VILA NOVA, S. Introdução à Sociologia. 5. ed. rev. e aum. São Paulo: Atlas, 2000.

Enviado em Agosto/2012

Aprovado em Novembro/2012 